\title{
Toward developmental models of psychiatric disorders in zebrafish
}

\author{
William H. J. Norton* \\ Department of Biology, College of Medicine, Biological Sciences and Psychiatry, University of Leicester, Leicester, UK
}

\section{Edited by:}

Gonzalo G. De Polavieja, Instituto

Cajal, Consejo Superior de

Investigaciones Científicas, Spain

\section{Reviewed by:}

Hitoshi Okamoto, RIKEN Brain

Science Institute, Japan

David Parker, Cambridge University, UK

\section{*Correspondence:}

William H. J. Norton, Department of Biology, College of Medicine, Biological Sciences and Psychiatry, University of Leicester, University Road, Leicester LE1 7RH, UK. e-mail:whjn1@le.ac.uk
Psychiatric disorders are a diverse set of diseases that affect all aspects of mental function including social interaction, thinking, feeling, and mood. Although psychiatric disorders place a large economic burden on society, the drugs available to treat them are often palliative with variable efficacy and intolerable side-effects. The development of novel drugs has been hindered by a lack of knowledge about the etiology of these diseases. It is thus necessary to further investigate psychiatric disorders using a combination of human molecular genetics, gene-by-environment studies, in vitro pharmacological and biochemistry experiments, animal models, and investigation of the non-biological basis of these diseases, such as environmental effects. Many psychiatric disorders, including autism spectrum disorder, attention-deficit/hyperactivity disorder, mental retardation, and schizophrenia can be triggered by alterations to neural development. The zebrafish is a popular model for developmental biology that is increasingly used to study human disease. Recent work has extended this approach to examine psychiatric disorders as well. However, since psychiatric disorders affect complex mental functions that might be human specific, it is not possible to fully model them in fish. In this review, I will propose that the suitability of zebrafish for developmental studies, and the genetic tools available to manipulate them, provide a powerful model to study the roles of genes that are linked to psychiatric disorders during neural development. The relative speed and ease of conducting experiments in zebrafish can be used to address two areas of future research: the contribution of environmental factors to disease onset, and screening for novel therapeutic compounds.

Keywords: zebrafish, psychiatric disorders, development, attention-deficit/hyperactivity disorder, autism spectrum disorder, schizophrenia, mental retardation

\section{INTRODUCTION}

Psychiatric disorders are a diverse group of diseases that can affect all aspects of mental function including thinking, feeling, mood, and sociability. Psychiatric disorders place a massive strain on society. They are the leading cause of disability in Europe and North America (Eaton, 2008) and rank second in the burden of diseases in established market economies (World Health Organisation [WHO], 2008). However, the drug therapies available to treat psychiatric diseases are often only palliative and have variable efficacy and side-effects. Many of the compounds used to treat psychiatric disorders were discovered serendipitously more than 50 years ago and have not been significantly improved since (WHO, 2008). Furthermore, the high costs associated with developing new treatments, estimated at roughly $\$ 1.8$ billion per drug, has prompted several major pharmaceutical companies to reduce or cancel their central nervous system research programs (Paul et al., 2010). One of the factors that have hindered the discovery of novel drugs is a lack of knowledge regarding the genetics and neurobiology of these diseases. Further research into the etiology of psychiatric disorders, driven by a combination of human genetic studies and animal models, and taking into account environmental influences, is needed in order to improve drug treatments and develop early prodomic interventions (before disease symptoms are visible) that could prevent or delay disease onset.

\section{THE ENVIRONMENTAL AND GENETIC BASIS OF PSYCHIATRIC DISORDERS}

Psychiatric disorders are caused by interaction of multiple factors that has been described by Gottesman and Gould (2003) as a "ballet that is choreographed over time between the action of multiple genes, environment and epigenetic factors." Initially, psychiatric disorders were thought to be triggered by the environment with only a limited influence of genes (Cooper, 2001). However, since the advent of genome-wide association studies (GWAS), there has been an increase in the amount of work that focuses on the genetic basis of psychiatric disorders. In parallel, data from twin family and adoption studies have uncovered heritability estimates for diseases such as schizophrenia (81\%), attention-deficit/hyperactivity disorder (ADHD, 80\%), and autism spectrum disorder (ASD, 70$80 \%$ ) suggesting a critical role for genetic lesions in these disorders (Sullivan et al., 2003; Bailey et al., 2005; Rosenberg et al., 2009; Banaschewski et al., 2010). Since it is difficult to study psychosocial interactions in animal models, this review will concentrate on the genetics of psychiatric disorders with a focus on alterations to early neural development. 
The genetics of psychiatric disorders are often complicated, with a non-Mendelian inheritance pattern and a continuous variation in phenotype suggesting that they might be caused by the action of multiple genes. This observation led to the common disease-common variant (CDCV) hypothesis: inheritance of one variant alone is not enough to cause a disease, but when combined with others a theoretical threshold will be passed and the disease triggered (Mitchell, 2011). As a result of the CDCV hypothesis, GWAS have been used to identify many genes associated with psychiatric disorders. GWAS are based upon the principle that multiple disease-causing variants (such as single nucleotide polymorphisms, SNPs) will be maintained in linkage-disequilibrium and so can be detected in an unbiased manner (Frazer et al., 2009). However, it is often unclear whether a loss or gain of gene function leads to expression of a psychiatric disorder. Following GWAS, mechanistic studies are then needed to show that identified variants participate in the disease being studied. Despite their promise, the contribution of GWAS to the understanding of psychiatric disorders has not been very impressive (Gottesman and Gould, 2003). Genes identified by GWAS still only account for a small percentage of the heritability of complex traits (Frazer et al., 2009) with poor correspondence of data across studies (Mitchell and Porteus, 2011). This is due to a combination of the modest effect of causative mutations on disease susceptibility, under-powered studies with small sample sizes, and the need to take environmental influences into account when studying genetic lesions.

Recent research has provided evidence that some psychiatric disorders, including schizophrenia, ADHD, autism, and mental retardation can also be triggered by mutations in single genes [sometimes referred to as the common disease rare variant (CDRV) hypothesis; Sebat, 2007; Walsh et al., 2008; Elia et al., 2009; Girirajan and Eichler, 2010; Williams et al., 2010; Geschwind, 2011; Lesch et al., 2011; Lionel et al., 2011; Veltman and Brunner, 2012]. Studies of families that suffer from psychiatric disorders often reveal de novo (or private) mutations which are unique to a given population or family. In fact, current estimates suggest that on average up to 74 novel mutations may occur per genome per generation in the non-disease population (Veltman and Brunner, 2012), with psychiatric disease families showing even higher than normal rates (Girard et al., 2011). These mutations are rare (comprising less than $1 \%$ of the minor allele frequency) and can either represent SNPs or be contained within copy number variations (CNVs) - deletions or duplications that can affect one or more genes at the same time (Sebat et al., 2009). CNVs occur quite frequently and have a mutation rate that is three to four times higher than other genomic areas, accounting for more genetic variation than other types of polymorphism (Cook and Scherer, 2008). Mutations can alter gene function in several ways, each of which can potentially lead to a psychiatric phenotype: they can activate proteins, create abnormal biochemical functions, or abrogate gene activity (Walsh, 1999; Walsh and Engle, 2010). Furthermore, a single gene can sometimes be mutated in multiple positions, each of which can trigger a different disease; whilst psychiatric disorders may be caused by a large number of different mutations, they might paradoxically only be linked to a small number of genes. For example, mutations in Disrupted in Schizophrenia 1 (Disc1) can lead to schizophrenia, bipolar disorder, major depressive disorder, and autism (Porteous et al., 2011). Similarly, a microdeletion at human chromosome locus 22q11 is associated with a range of diseases including schizophrenia and velocardiofacial syndrome, anxiety, depression, ADHD, obsessive-compulsive disorder, and ASDs (Gothelf et al., 2004). Thus, seemingly diverse diseases may share a common genetic basis, making it possible to identify disease-causing variants in known - rather than novel genes in some cases.

The relative contribution of rare or common mutations to disease susceptibility is not known. Psychiatric disorders could be caused by a combination of several types of genetic lesion rather than a single mutation alone (Veltman and Brunner, 2012). Single mutations might predispose patients to mental illness, while other SNP polymorphisms in the genetic background (or mutations in a second critical gene) could alter disease penetrance (Girirajan and Eichler, 2010; Mitchell and Porteus, 2011). Therefore, a single mutation may be necessary but not sufficient to trigger the disorder. Such a combined model would explain the large heterogeneity of symptoms and the low penetrance that is sometimes observed. The potential interaction between rare and common mutations in the etiology of mental disease is reminiscent of the genetics of cancer. According to Knudson's two-hit hypothesis, cancer can be triggered by the combination of two or more mutations (Knudson, 1971). A recessive germline mutated allele is inherited from one parent, followed by a novel somatic mutation in the same gene (Guidry and Kent, 1999). The combination of common variants and rare mutations associated with psychiatric disorders raises the possibility that psychiatric disorders may also be caused by loss of heterozygosity or by the inheritance of two "hits" in separate genes (Girirajan and Eichler, 2010; Toro et al., 2010). The considerable number of brain areas and processes affected by psychiatric disorders provide a large pool of mutable genes which could lead to expression of a disease (Xu et al., 2008). As an example of this, CNVs in both NRXN1 and CNTNAP2 have been linked to PittHopkins-like syndrome, a familial disease that includes autistic symptoms (Zweier et al., 2009). Patients with Pitt-Hopkins-like syndrome have been found to have lost one copy of NRXN1 or CNTNAP2 coupled to a deleterious point mutation in the second allele of the same gene (Toro et al., 2010).

Interestingly, phylogenetic analysis of disease-causing mutations suggests that our current classification of psychiatric disorders may be based upon culturally acceptable behavioral norms. For example, in the case of the ADHD-linked gene LATROPHILIN3, the disease-causing variant is ancestral with protective variants arising over time (Arcos-Burgos et al., 2010; Domene et al., 2011). Thus some of the symptoms of ADHD including hyperactivity and impulsivity - were either advantageous or at least not selected against during evolution. Similar results have been found for Calretinin polymorphisms linked to schizophrenia (Farokhashtiani etal., 2011), with diseasecausing variants found in other distantly related vertebrate species.

The interaction of genes with environmental factors (including infection, drugs, malnutrition, psychosocial adversity, or obstetric complications) is likely to play a significant role in the risk of suffering from a psychiatric disorder. Genes may predispose 
people to suffer from a disease, which is triggered when an adverse environment is encountered. Thus the severity of a disease might be determined by the interaction of a single gene with different environmental factors. These environmental factors may also be under genetic control. For example, the genetic variants that cause maternal ADHD also increase the propensity of mothers to drink or smoke (Castellanos et al., 1996; Laucht et al., 2007; Thapar et al., 2009). Furthermore, the number of germline mutations in sperm increases with age, exacerbating the likelihood of suffering from psychiatric disorders such as autism (Veltman and Brunner, 2012). In some cases, environmental influences may ultimately reflect the interaction of the parent's and child's genomes in expression of mental illness (Castellanos et al., 1996; Laucht et al., 2007). The gene-by-environment $(\mathrm{G} \times \mathrm{E})$ interactions that lead to psychiatric disorders are poorly understood. However, a recent study of the human ADHD-risk gene LATROPHILIN3 suggests that $\mathrm{G} \times \mathrm{E}$ interactions may not have a linear impact upon disease susceptibility (Choudhry et al., 2012). In impoverished environments (such as maternal stress during pregnancy), mutation of LPHN3 has little contribution to disease onset with environmental factors playing a major role. However, in adequate or enriched environments, polymorphisms in $L P H N 3$ have a greater chance to trigger the disorder (Choudhry et al., 2012).

\section{ALTERATIONS TO EMBRYONIC DEVELOPMENT CAN LEAD TO PSYCHIATRIC DISORDERS}

Many of the rare mutations linked to psychiatric disorders are found in genes that are active during embryonic development. Subtle disruptions to the homeostasis of normal development can have far-reaching consequences that lead to permanent alterations in the function of the mature brain (Mitchell, 2011). Psychiatric disorders can thus be conceptualized as deviations in the normal trajectory of embryonic development within acceptable noise levels resulting in non-lethal modifications of behavior (West-Eberhard, 2005). Genetic variation and developmental plasticity (including chance events) are a fundamental property of all living organisms and provide the raw material upon which evolution can act. Development thus constitutes a series of branching pathways in which developmental decisions switch between different potential endpoints (West-Eberhard, 2005). For example, dopaminergic neurons show a surprisingly stochastic wiring pattern in larval zebrafish, even though they are thought to be genetically homogenous (Tay et al., 2011). Extreme alterations to embryonic development are likely to be lethal. However, if a mutation coincides with a chance event, a subtle change to embryonic development that leads to a psychiatric disorder may occur. Alterations to neural development can act at the cellular or circuit level. In some cases mutations may cause specific phenotypes linked to neurological disorders, such as the control of cell division, migration, differentiation, and survival, or changes to neurite outgrowth, axon pathfinding, and dendritic architecture (Thornton and Woods, 2009; Valiente and Marin, 2010). Alternatively, mutations may cause more diffuse and variable alterations to brain function: miswiring of neural circuits, disinhibition of local interneurons, or adjustment of normal brain homeostasis leading to pathophysiology (Lisman et al., 2008), a process which has been called "developmental disconnection" in relation to ASDs
(Geschwind and Levitt, 2007). Diffuse changes to brain function seem particularly likely to lead to psychiatric diseases when considering that genes do not directly control behavior, but rather act via the formation, connection, and function of neural circuits.

\section{TRANSLATIONAL MODELS OF PSYCHIATRIC DISORDERS IN ZEBRAFISH}

Although recent studies have uncovered many genes linked to psychiatric disorders, only few of them have been experimentally validated. Therefore, mechanistic studies are required in order to investigate whether a loss- or gain-of-function contributes to disease pathology in each case. The complex genetic basis of psychiatric disorders makes it difficult to fully recreate them in animal models. Thus, the challenge of studying these diseases consists of integrating basic molecular data from animals with information about complex human mental functions at the circuit level (Geschwind, 2008). One way to simplify this problem is to measure endophenotypes, neuropsychological or biological markers that correlate to a disease-gene's activity (Gottesman and Gould, 2003; Kendler and Neale, 2010). An ideal endophenotype should be controlled by a single gene, be associated with expression of the disease in the population and be both heritable and state independent (meaning that it is expressed even when the illness is not active; Rommelse, 2008). Although in animal models endophenotypes have rarely fulfilled all of these criteria, their use may simplify the translation of information to human patients. Furthermore, the division of psychiatric disorders according to endophenotypes may help refine their diagnosis; diseases could thus be reclassified on the basis of their molecular pathology instead of behavioral or psychological symptoms, providing an explanation for comorbidity with other disorders (Gottesman and Gould, 2003).

Despite the difficulty of modeling psychiatric disorders, animal studies still have the potential to give insights into the etiology of mental illness. The advent of tools to manipulate genes has now allowed the creation of animal models that are firmly based upon the genetic pathways underlying a disease. A perfect animal model should have three main attributes: construct validity (meaning that it conforms to the underlying rationale of the disease), face validity (mimicking some of the characteristics of the disease), and predictive validity (the ability to accurately predict outcomes or symptoms in humans; Sarter et al., 1992; Einat et al., 2003; Arime et al., 2011). The animal model should also combine genetic tractability, tools to visualize and manipulate neurons in vivo, and the ability to translate findings to patients based upon conserved neurobiology.

Zebrafish have already been established as a powerful model for developmental biology and neuroscience. Zebrafish develop rapidly outside of the mother making it easy to collect and manipulate embryos. By 6 days, larval fish swim continuously, search for food, and are able to escape from predators thus demonstrating a range of behaviors. Zebrafish are transparent until larval stages allowing the study and manipulation of neural circuits at the cellular level in the intact brain (Fetcho and Liu, 1998). Furthermore, a large number of identified mutant lines, genetic tools such as TALENs (transcription activator-like effector nucleases) and zinc-finger nucleases to knock-out genes; Amacher, 
2008; Huang etal., 2011; Sander et al., 2011), genetic ablation (Curado et al., 2007), optogenetics (Nagel et al., 2003; Zhang et al., 2007), and techniques to monitor neural activity (including calcium indicators and electrophysiology; Higashijima et al., 2003) have already been established. Although the formation, position, and function of neurotransmitter signaling pathways sometimes differ between zebrafish and other vertebrates, comparative studies are beginning to precisely map these differences, allowing the transfer of information gained in zebrafish to other species (Tropepe and Sive, 2003). Furthermore, a battery of tests for behavioral analysis of both larval and adult zebrafish has already been developed (Fero et al., 2011; Norton and Bally-Cuif, 2010; Norton etal., 2011). Although tools to study neuroscience are already available in other genetically tractable vertebrates such as mouse, the ease of generating large numbers of zebrafish and their transparency make them ideal for high-throughput analyses and imaging studies. As a model for behavioral neuroscience, the zebrafish is particularly useful for optogenetic dissection of the behavior, time-lapse analysis of neurotransmitter pathway formation during development and screening for novel therapeutic treatments. For example, the compensatory changes to neurotransmitter signaling pathways that occur following genetic manipulation can be examined in zebrafish. Abrogation of a single gene will most likely lead to the modification of multiple neurotransmitters. These fluctuations could be examined in two ways. The levels of neurotransmitters in the brain could be measured directly by either high pressure liquid chromatography (HPLC) or an enzyme-linked immunosorbent assay (ELISA). Alternatively, the alterations to neural circuits in the brain could be uncovered using calcium indicators driven by neurotransmitter-specific promoters [such as otpb. A for dopamine (DA; Fujimoto et al., 2011) or pet1 for serotonin (5-HT; Lillesaar et al., 2009)]. Neural activity (detected as flashes of calcium signaling) could be measured in fish lacking a functional copy of an ADHD-linked gene. This information might provide clues about the signaling pathways and brain areas underlying a phenotype and so provide avenues for future research.

The power of zebrafish to study developmental biology suggests that it may make important contributions to the study of genes associated with psychiatric disorders. The zebrafish homologs of genes linked to psychiatric disorders can be identified, and their basic function during neural development (related to neural circuit formation or behavior for example) analyzed following manipulation. For example, a zebrafish line could be created which harbors a mutation mimicking the situation in human patients. This could include replacing the wild-type zebrafish transcript with a humanized form of the gene or knocking the gene down by TALEN or morpholino injection. The developmental and behavioral phenotype of the manipulated fish could then be characterized. Environmental interactions with these models could be studied by applying standardized environmental manipulations - for example, by stressing the fish before testing behavior (Amir-Zilberstein et al., 2012), growing embryos in a hypoxic environment (Marks et al., 2005) or treating with alcohol or nicotine (see below). The data generated by this approach could then be verified in rodents and if similar results are obtained then clinical trials would be initiated. Apparent behavioral similarities between animals (which are often used to develop models of human diseases) may not ensure that the same underlying process is being measured, since each behavior might not serve the same purpose in all species. In contrast to this, developmental models of psychiatric disorders may have improved construct validity if the model is based upon the same underlying changes to development which lead to expression of the disease.

In the following section, I will briefly summarize zebrafish models of ADHD, schizophrenia, ASDs, and X-linked mental retardation (XLMR).

\section{ZEBRAFISH MODELS OF ADHD}

Attention-deficit/hyperactivity disorder is a common neuropsychiatric disorder that is characterized by developmentally inappropriate inattention, hyperactivity, and impulsivity. It affects around $3-5 \%$ of children worldwide regardless of nationality or cultural setting (Swanson et al., 1998; Polanczyk et al., 2007). The symptoms of ADHD persist into adulthood in about $50 \%$ of cases and can lead to a reduction in the quality of the sufferer's life including impairment of academic, behavioral, and social performance (Barkley et al., 2006; Schmidt and Petermann, 2009). ADHD patients are also more likely to suffer from other psychiatric disorders, including depression, anxiety, and substance use disorder (Molina and Pelham, 2003; Lesch et al., 2008; Sharp et al., 2009). Data from drug treatments and genetic analyses have suggested that alterations in DA and noradrenaline (NA; and to a lesser extent 5-HT and glutamate) signaling most likely underlie the symptoms of ADHD. For example, methylphenidate (MPH), an amphetamine like compound that increases both DA and NA levels in the prefrontal cortex (Berridge et al., 2006) can be used to manage ADHD and so has orientated research toward monoaminergic signaling. ADHD patients are thought to have a reduction of dopaminergic signaling in the prefrontal cortex. Other brain areas which have been connected to ADHD include the striatum (caudate nucleus and putamen) the parietal cortex and both the vermis and the inferior lobes of the cerebellum (Berquin et al., 1998; Arnsten, 2007; Bush, 2010; Rubia, 2011).

Multiple DA pathway-related genes have been linked to ADHD. Association with polymorphisms in the gene encoding the DA D4 receptor (DRD4; Ebstein et al., 1996; LaHoste et al., 1996), the DA D5 receptor (DRD5; Hawi et al., 2002), and the DA transporter gene (DAT/SLC6A3; Cook et al., 1995) have been reported. Most studies of DAT have focused on a 40 base-pair variable number tandem repeat (VNTR) found in the $3^{\prime}$ untranslated region (UTR) of the gene (Vandenbergh et al., 1992; Curran et al., 2001; Purper-Ouakil et al., 2005). There is also some evidence associating the DA synthesis enzyme Dopamine-beta hydroxylase $(\mathrm{DBH})$ and the disease (Comings et al., 1996). In the 5-HT pathway, the 5-HT synthesis enzymes TPH1 and TPH2 (Walitza et al., 2005; Li et al., 2007) and the 5-HT transporter gene (SERT/SLC6A4; Gizer et al., 2009) have all been linked to ADHD formation. Recent GWAS and candidate gene studies have also identified polymorphisms in genes that are involved in cell adhesion (including ASTN2 and CDH13) and synaptogenesis (SNAP25, CTNNA2, and KLRN; Faraone et al., 2005; Lesch et al., 2011). Thus, as well as being caused by direct modification of neurotransmitter signaling, ADHD may be triggered by more general alterations in 
brain formation, including cell-signaling, morphogenesis, and migration during development.

There is currently only one study that has reported the use of fish to directly study an ADHD-linked gene (Lange et al., 2012). Lange et al. (2012) have studied latrophilin3.1, a zebrafish homolog of the human ADHD-susceptibility gene LATROPHILIN3. LPHN3 was identified by linkage analysis of a genetically isolated European population in Columbia, followed by fine-mapping of several North American and European populations (Arcos-Burgos et al., 2010). Recent research has identified two families of endogenous ligands for Latrophilin3, the Teneurins and the FLRTs (Fibronectin Leucine-rich repeat transmembrane proteins; Silva et al., 2011; O'Sullivan etal., 2012). latrophilin3.1 is one of two zebrafish homologs of human LPHN3, both of which are expressed in differentiated neurons throughout the brain up to 6 days post fertilization. lphn3.1 morphants show an increase in the distance swum at 6 days, a hyperactive phenotype. This hyperactivity is also maintained during the night suggesting a permanent increase in locomotion compared to animals injected with a control morpholino. Furthermore, $l p h n 3.1$ morphants also show an increase in the number of bursts of acceleration while swimming indicative of motor impulsivity. Both hyperactivity and motor impulsivity can be rescued by applying the ADHD treatment drugs MPH and atomoxetine. Acute treatment of either drug had no effect on control-injected larval behavior at the doses used (10 $\mu \mathrm{M} \mathrm{MPH}$ or $1 \mu \mathrm{M}$ atomoxetine for $1 \mathrm{~h}$ ), but rescued morphant behavior bringing locomotion back to control levels. Iphn3.1 morphants also display a parallel reduction of dopaminergic cells in the posterior tuberculum (PT), a prominent group of dopaminergic neurons in the ventral diencephalon that controls larval locomotion (Bretaud et al., 2004; Sallinen et al., 2009; Tay et al., 2011). Recent analysis of the molecular signature and projection pattern of zebrafish PT neurons suggests they are similar to mammalian hypothalamic A11 DA neurons (Tay et al., 2011). Similar to A11, individual PT DA neurons project both anteriorly and posteriorly with the majority of projections ( $80 \%$ ) going to the spinal cord (Ryu et al., 2007; Tay et al., 2011). Lesion of A11 DA neurons in rat causes a restless legs syndrome (RLS)-like hyperactivity phenotype and comorbidity between RLS and ADHD has been observed (Cortese et al., 2005). Thus common genes and neural circuits might underlie both diseases in mammals. Regardless of the homology of the zebrafish PT with other species, $l p h n 3.1$ appears have a critical role in controlling the development of dopaminergic neurons (Lange et al., 2012), a finding which has recently been confirmed in mice (Wallis et al., 2012).

\section{ZEBRAFISH MODELS OF SCHIZOPHRENIA}

Schizophrenia is a severe psychiatric disorder whose symptoms include mood changes (such as delusions and hallucinations), disorganization of thought, agitated body movements, anhedonia, depression, speech problems, and a lack of motivation. Although schizophrenia is thought to be caused by defects in early brain development (Weinberger, 1995), disease symptoms often do not appear until the second or third decade of life (typically between 16 and 30 years of age). Schizophrenia affects around $1 \%$ of the adult population in the USA according to the National Institute of Mental Health. Twin studies give a heritability estimate of about
$81 \%$ for schizophrenia, and an environmental effect (including variables such as diet, parenting style, and exposure to toxins or teratogens) of around 11\% (Sullivan et al., 2003). A large number of schizophrenia cases are sporadic, appearing for the first time in a family with no previous history of the disease (Xu etal., 2008). Rare de novo CNVs are one mechanism that can account for sporadic cases. In agreement with this, schizophrenia patients carry more CNVs than the general population and also have a higher than normal de novo mutation rate (Girard et al., 2011, 2012).

Neurobiological studies have identified defects in the frontal and temporal lobes of schizophrenia patients. Many schizophrenics also have enlarged cerebral ventricles linked to a 5-10\% reduction in gray matter volume in the absence of gliosis, suggesting that loss of tissue is not caused by degeneration (Mueser and McGurk, 2004). Both dopaminergic and glutamatergic neurotransmission has been linked to the disease. For example, a reduction of blood flow in the prefrontal cortex related to DA activity has been documented in schizophrenia patients (Mueser and McGurk, 2004). Many genes have been connected to the susceptibility to suffer from schizophrenia. For example, genes with particularly strong linkage to the disease include DISRUPTED IN SCHIZOPHRENIA1 (DISC1), NEUREGULIN1, DYSTROBREVIN BINDING PROTEIN1 (DTNBP1), KIF1, KIF17, SHANK3, and NOTCH4 (Tarabeux et al., 2010; Girard et al., 2012). Developmental processes which might be affected include genes which affect neural proliferation, differentiation, and migration during development or abnormal myelination in the schizophrenic brain (Flynn et al., 2003).

Although it is not possible to study the positive symptoms of schizophrenia such as disordered thought, delusions, and hallucinations in zebrafish, the basic developmental function of genes linked to this disease can still be studied. For example, schizophrenia candidate genes may be important for neurogenesis, neuronal migration, and cell fate determination (Morris, 2009). Burgess and Granato (2007) have developed a schizophrenia endophenotype in zebrafish: prepulse inhibition (PPI). PPI is a type of sensorimotor gaiting (a reduction of startle response that occurs when preceded by a weak non-startling stimulus) that is impaired in schizophrenic patients (Braff et al., 2007). Zebrafish PPI is modified by both apomorphine and ketamine [which affect DA and $N$-methyl- $D$-aspartate (NMDA) signaling respectively] and thus appears to be mediated by similar neurotransmitters as in other animals. Five novel mutant lines with abnormal PPI responses were also identified in the same study. Characterization of these mutants might give novel insights into the genes and brain areas that control behaviors linked to schizophrenia.

One of the most intensely studied schizophrenia-related genes is DISC1, which was first identified in a Scottish pedigree displaying high incidence of depression, schizophrenia, and bipolar disorder (Millar et al., 2000). DISC1 has subsequently been shown to be involved in neurogenesis, neural migration, axon growth, synaptogenesis and function, dopaminergic neuron function, and cell-cell adhesion. Studies of discl in zebrafish have provided novel information about the function of this gene. De Rienzo et al. (2011) have shown that discl has a critical role in both the canonical ( $\beta$-catenin-mediated) and non-canonical Wnt signaling 
pathways during embryonic development. Furthermore, different humanized forms of disc1 have been shown to activate different signaling pathways in zebrafish. For example, Ala38Val, Arg264Gln, and Leu607Phe disc1 variants interact with canonical Wnt signaling, whereas a Ser704Cys variant modifies neuronal migration via the cytoskeletal genes $n d e 1$ and $d i x d c 1$ (Singh et al., 2011). disc1 has also been shown to control oligodendrocyte proliferation, a phenotype that can also be generated by inhibiting the schizophrenia-susceptibility genes neuregulin1 and its receptor erbb4 (Wood et al., 2009).

There have been several studies that have characterized schizophrenia-related genes in zebrafish. For example, the connection between Akt signaling, dopaminergic neurotransmission, and schizophrenia has been investigated. Cheng et al. (2013) have used zebrafish to study $\mathrm{rgs}$, a regulator of G-protein signaling family that is expressed in the developing nervous system. Loss of gene function causes both neurite outgrowth defects in the hindbrain and spinal cord and a reduction of motility. Activation of Akt signaling can rescue the outgrowth phenotype in the spinal cord but not hindbrain, indicating that Akt signaling is required for some rgs4-mediated axon formation (Cheng et al., 2013). Souza etal. (2011) have further examined the connection between Akt signaling and dopaminergic neurotransmission in the developing brain. Since alterations in Akt signaling have also been linked to schizophrenia, this strengthens the suggestion that altered dopaminergic signaling during development might underlie the disease. Other human disease-causing genes have been studied as well. Knock-down of the synaptically expressed schizophrenia-susceptibility gene kinesin17 (kif17) causes a severe phenotype in zebrafish embryos including stunted development and a curly tail phenotype suggesting that kif17 is active during embryonic development (Tarabeux et al., 2010). Finally, treatment of zebrafish with the NMDA receptor antagonist MK-801 causes several behavioral alterations including changes to social interaction, hyperactivity, and amnesia, which have been interpreted as being schizophreniform (schizophrenia-like; Chen et al., 2010; Seibt etal., 2010, 2011; Echevarria etal., 2011) and are similar to the behavioral changes elicited by these psychotics in rodents.

In summary, although it is not possible to model some of the more complex psychological symptoms of schizophrenia in fish, several recent studies have given insights into some of the basic processes underlying this disease.

\section{ZEBRAFISH MODELS OF AUTISM SPECTRUM DISORDER}

Autism spectrum disorder encompasses a range of psychiatric diseases including autism (the severest form of ASD), Rett's syndrome, and Asperger's syndrome. The symptoms of ASD are highly variable between patients making it difficult uncover the genetic and neurobiological changes that underlie these disorders. Broadly speaking, the main symptoms of ASD include alterations in social behavior, repetitive behavior, and language development that appear before 3 years of age (Lord et al., 2000). There is a heritability estimate of between 70 and $80 \%$ for ASD (Bailey et al., 2005; Rosenberg etal., 2009). However, the number of people thought to suffer from ASD is increasing over time which might be due to a shift in the diagnostic criteria used (Lord, 2010).
Although it is not possible to study complex behaviors such as language development in fish, a few recent studies have provided information about the function of ASD-linked genes during neural development.

Both common and rare (de novo) genetic variants, acting in combination with environmental influences, are associated with ASD. ASD-linked polymorphisms are predominantly found in genes that regulate synapse development, cell proliferation, neural migration, and neural projection. Rare mutations seem to account for around 10\% of cases of ASD (Geschwind, 2008). It has been suggested that there may be a different genetic basis for simplex families (where only one child is affected and rare mutations are common) and multiplex families (where multiple genetic variants lead to ASD expression in several family members; Geschwind, 2008). For example, there is a higher frequency of CNVs in ASD families with only one affected child compared to those with two or more ASD children (Toro et al., 2010). Interestingly, there is also some data suggesting that rare and common variants interact to trigger ASD symptoms (Ben-David and Shifman, 2012). Genes which have been linked to ASD include the Fragile X gene FRAGILE $X$ MENTAL RETARDATION 1 (FMR1), the GABA A $\beta 3$ subunit gene GABRB3 as well as SHANK3, TSC1, NEUROLIGIN3 and NEUROLIGIN4, PTEN and CNTNAP2 (Cook and Scherer, 2008; Geschwind, 2008, 2011; Lord, 2010) amongst others. The neurobiology of ASD is not well understood, but most likely includes brain areas which are needed for the control of social behavior and language. For example, altered connections between the frontal lobe (the orbitofrontal cortex) and temporal lobe (including the superior temporal gyrus and temporal polar cortex) may mediate some symptoms of the disease (Geschwind, 2011). Other important brain areas include the cerebellum, brainstem, and limbic areas including the hippocampus, amygdala, septal nuclei, and the anterior cingulate cortex (Lord et al., 2000). Finally, autism has also been related to megalencephaly, an overall increase in brain size in some patients.

Since the symptoms of ASD first occur during neural development it is possible to study the early function of ASD-related genes in this species (Tropepe and Sive, 2003). There are only a few research articles reporting the use of zebrafish in this type of research. In humans, a CNV at $16 \mathrm{p} 11.2$ has been associated with susceptibility to suffer from several disorders, including ASD, epilepsy, autism, and schizophrenia. The 16p11.2 CNV has been studied in zebrafish by two groups (Blaker-Lee et al., 2012; Golzio et al., 2012). In a landmark study, Golzio et al. (2012) analyzed 24 of the genes contained within this CNV and identified one, KCDT13, as most likely being causative for the disease. Overexpression of $k c d t 13$ (by mRNA injection) led to microcephaly, whereas gene-specific morpholino knock-down caused an increase in head size, likely due to alteration of the cell cycle in both cases. This study provides a neat demonstration of the use of zebrafish to identify disease-causing variants within large genomic regions. Gauthier et al. (2010) have used morpholinos to knockdown SHANK3, a gene linked to schizophrenia and ASD in human patients. shank3 morphant zebrafish show decreased swimming after being touched, a phenotype which can be rescued with a wild-type (but not a mutant) version of the corresponding rat gene. Therefore, this study validated alterations to shank 3 as being 
important in the control of behavior, with potential implications for both schizophrenia and ASD.

\section{ZEBRAFISH MODELS OF MENTAL RETARDATION}

Mental retardation constitutes a significant impairment of cognitive function that can be symptomatic of a number of underlying neural defects. In this review, I have chosen to focus on XLMR (also called Fragile X syndrome, FXS) a common inherited form of mental retardation which affects around 1 in 4000 people. However, zebrafish have also been used to examine other types of mental retardation (for recent studies, refer to Komoike et al., 2010; Song et al., 2010; Brockschmidt et al., 2011; Friedrich et al., 2012; Veleri et al., 2012; Aspatwar etal., 2013). The symptoms of FXS include mental retardation, epilepsy, autistic-like behavior, attention deficits, macroorchidism, and mild craniofacial defects which have been linked to the maturation of dendritic spines during development.

Similar to schizophrenia and ASD, it is likely to be impossible to model the cognitive symptoms of mental retardation in fish. However, several zebrafish groups have analyzed XLMR-linked genes and provided information about their role during development. For example, XLMR is most often caused by mutations in the FMR1 gene, which contains a variable CGG trinucleotide repeat sequence in its 5' UTR (Verkerk etal., 1991). Once this repeat passes 200 copies, the gene becomes hypermethylated and loss of function occurs. Interestingly, this methylation appears to be mediated by a microRNA which is present in the $3^{\prime}$ UTR of FMR1, an observation which has been experimentally confirmed in zebrafish (Lin et al., 2006). Injection of a construct targeting the anti-fmr1 miRNA causes abnormal neural morphology and an increase in the size of the head (Lin et al., 2006).

Studies of the zebrafish homolog of the FMR1 gene have given equivocal results. Intriguingly, different phenotypes were observed when comparing morpholino-mediated knock-down and a stable fmr1 mutant line. Morphant larvae show craniofacial defects, hydrocephaly, and pericardial edema as well as abnormal branching of the trigeminal ganglion and lateral longitudinal fasciculus (Tucker et al., 2006). However, in contrast to this, fmr1 mutant larvae are adult viable and show no detectable morphological differences (Den Broeder et al., 2009). Thus, it is clear that further studies are needed in order to fully understand the function of this gene during development. Qi et al. (2010) studied the XLMR gene phf8 during zebrafish development. phf 8 is a mono-methyl histone H4 lysine 20 demethylase that is expressed in the developing head and jaw of zebrafish at 1 day. Loss of gene function causes severe disruption to development of these structures, most likely caused by increases in apoptosis (Qi et al., 2010). Histone methylation has also been linked to XLMR in a study of the $s m c x / j a r i d 1 c$ gene, a H3K4 demethylase (Iwase et al., 2007). Loss of smcx function during development leads to increased cell death and a smaller brain as well as a reduced number of dendrites. Together, both of these studies suggest that epigenetic events might play an important role in the etiology of XLMR. Another XLMR-linked gene, $r b m x$, shows strong expression in the anterior developing embryo including the brain (Tsend-Ayush et al., 2005). Knock-down of $r m b x$ leads to a reduction in body size, pericardial edema, hydrocephaly, and reduced motility (Tsend-Ayush et al., 2005). Finally, the non-syndromic mental retardation genes illrapl1a, illrapllb, and illrapl2 (zebrafish homologs of human IL1RAPL, which is located on the $\mathrm{X}$ chromosome) are widely expressed throughout the brain. Knock-down of one of the homologs, ilraplib, inhibits presynaptic differentiation during development (Yoshida and Mishina, 2008).

There are several learning and choice discrimination tests that have been developed for adult zebrafish which could be used to test possible cognitive functions of mental retardation-associated genes. For example, Brennan and colleagues have developed a 3-choice serial reaction time task (3CSRTT) that can be used to measure impulsivity (Parker etal., 2012). The 3CSRTT is measured in a tank that has a green light-emitting diode (LED) on one side and three yellow LEDs in separate compartments on the other. Following illumination of the green LED, adult zebrafish are taught to only enter the compartment where the yellow LED is switched on. The correct execution of this behavior is reinforced with a food reward. Following a training period in which the fish learns to associate the yellow light with a reward the 3CSRTT can begin. The green stimulus LED is first activated and is then followed by a 10-s intertrial interval (ITI). Following this pause, one of the yellow LEDs is lit and the fish is rewarded with food upon entering the correct compartment. However, entry into any compartment before the end of the ITI, perhaps indicative of impulsivity, will result in a punishment (a 10-s time-out with no food). Entry into an incorrect compartment on the other side (i.e., one in which the yellow LED is not illuminated) will also trigger the punishment. Other tests of learning and memory, including associative-, avoidance-, and spatial memory have also been established (reviewed in Norton and Bally-Cuif, 2010). Although these tests appear to be promising in to study zebrafish cognition, they have mostly only been tested on wild-type fish and so need further validation (for example, in fish lacking the function of a diseaselinked gene) before they can be proposed as retardation-linked phenotypes.

\section{FUTURE DIRECTIONS FOR RESEARCH INTO PSYCHIATRIC DISORDERS USING ZEBRAFISH}

The functions of genes linked to psychiatric disorders are still relatively understudied in zebrafish. However, the power of zebrafish as a model organism to study neural development and behavior suggest that there are several areas in which the zebrafish has the potential to provide more information related to these diseases, as discussed below.

\section{ENVIRONMENTAL CONTRIBUTIONS TO DISEASE ONSET}

Since zebrafish embryos develop outside of their mother, it is easy to manipulate their environment and so carry out $\mathrm{G} \times \mathrm{E}$ studies. Although it is not possible to model adverse psychosocial environments (such as parenting styles) in fish, other environmental factors including exposure to alcohol or nicotine could easily be studied. Ethanol exposure during development causes a range of phenotypes depending on the timing and concentration used, making it difficult to get an overview of the mechanism underlying the action of this drug, or how it might relate to alcohol-related changes to behavior in humans. At concentrations greater than $2 \%$, ethanol causes gross body abnormalities including cardiac edema, 
cyclopia, and dysmorphia (Blader and Strahle, 1998; Sylvain et al., 2010). Lower concentrations trigger behavioral alterations in the absence of obvious morphological changes. For example, transient exposure to ethanol can lead to either locomotor hyperactivity (Tal et al., 2012), a reduction of swimming coupled to defects in secondary motorneuron development and synaptogenesis (Sylvain et al., 2010, 2011) or reduced shoaling in adult fish (Fernandes and Gerlai, 2009; Buske and Gerlai, 2011). Embryos which are treated with nicotine during development tend to be smaller, with a permanent delay and disruption of secondary motorneuron development (Svoboda et al., 2002; Menelaou and Svoboda, 2009). Nicotine also causes a transient increase in swimming speed, followed by a long-lasting reduction in both startle response and swimming speed, a phenotype which is most likely mediated via activation of nAChRs (Svoboda et al., 2002; Eddins et al., 2010).

One of the difficulties of designing $\mathrm{G} \times$ E studies, highlighted by the examples related to ethanol and nicotine, will be to mimic the situation in nature as closely as possible. Although environmental alterations may modify the severity of an obvious pre-existing phenotype, in some cases environmental influences would be expected to trigger disease-related symptoms in a genotype that initially looks normal. One way to address this issue would be to develop a zebrafish transgenic line that contains a humanized form of the disease-risk gene and then subject embryos to different environmental conditions (such as varying concentrations of ethanol or nicotine exposure) before measuring behavior. Although such an approach is not more technically difficult than starting with a measurable behavioral change, it would require researchers to have more confidence when developing the assay.

\section{SCREENING FOR NOVEL DRUGS}

Zebrafish are a good model system for pharmacological studies, since compounds can be diluted in the embryo medium, and larvae are transparent meaning that internal organs can be visualized throughout development (Peterson et al., 2000). Furthermore, larvae are small, easy to generate in large numbers and easy to manipulate making them ideal for high-throughput work. However, since screens that use behavior as a read-out are difficult to design and implement efficiently (particularly if focusing on complex behaviors other than locomotion), it might be easier to carry out an initial pre-screen of a disease endophenotype. For example, zebrafish lacking the function of the ADHD-linked gene lphn3.1 show a reduction and displacement of dopaminergic neurons in the PT of the diencephalon (Lange et al., 2012). Pre-screening libraries for compounds which can rescue this phenotype might speed up the screening process, with a subset of promising drugs then being re-tested to assess their behavioral function.

Two studies have combined analysis of underlying chemical structure and high-throughput screening of chemical libraries to look for alterations to the photomotor response, an embryonic motor response to a series of light flashes (Kokel et al., 2010; Laggner et al., 2012). This assay can be performed in a 96-well plate, and can be scaled up to analyze around 5000 novel chemicals every day. Rihel et al. (2010) uncovered the effect of drugs on locomotor activity across different sleep/wake cycles, providing novel information about neuroactive drugs which can affect behavior. In this study, chemicals were categorized according to their "behavioral fingerprint," a combination of their chemical structure and their ability to modify aspects of behavior, thus permitting prediction of the function of novel chemicals.

A screen for novel anti-epileptic drugs was conducted in 2-dayold zebrafish embryos by Baxendale et al. (2012). Although not a developmental psychiatric disorder, this work further demonstrates the utility of zebrafish for drug identification. Exposure of embryos to the convulsant pentylenetetrazole (PTZ) upregulates expression of the immediate-early gene fos in the brain. The level of fos expression (assayed by in situ hybridization) was then used to screen a bioactive small-molecule library with a hit rate of $2.3 \%$ for anti-convulsive drugs (Baxendale et al., 2012). Using a similar approach, Baraban (2007) screened for novel zebrafish mutant lines which are resistant to the seizure-inducing properties of PTZ at 7 days post fertilization. Six novel mutant lines were identified, raising the possibility of uncovering novel genes with a seizure-protective function. The effects of the stimulants ethanol, amphetamine, and cocaine on larval swimming behavior have also been reported (Irons et al., 2010). Whilst not high-throughput, this study demonstrates the ease of screening motor behavior in 96-well plates, meaning that this paradigm could potentially be used to look at hyperactivity or startle, endophenotypes related to psychiatric disorders.

Although zebrafish constitute a power model system for drug screens, further experiments will be required before data can be translated to human patients. In a first step, the results will need to be verified in a second animal model - most likely a knockout mouse harboring a similar genetic lesion. Analysis of further disease models with and without drug treatment will provide information about selectivity of the chemical compound for one or more signaling pathways. A drug with a similar profile in both fish and mouse will represent a very promising target for clinical trials as long as no toxic effects are detected.

\section{CONCLUSION}

A full understanding of the basis of psychiatric disorders requires the characterization of complex behaviors such as thought, feeling, and emotion, most likely through translational experiments in a combination of model organisms such as zebrafish and rodents. However, the suitability of zebrafish for developmental studies, and the genetic tools which are available to manipulate them suggest that the early development function of psychiatric disorder-linked genes can be studied in this model organism. Studies of genes linked to ADHD, schizophrenia, ASD, and mental retardation that have been performed in zebrafish have already demonstrated the validity of this approach. I look forward to future developments in this exciting field.

\section{ACKNOWLEDGMENTS}

I am grateful to Marion Coolen, Merlin Lange, and Mike Jay for critically reading an earlier version of this manuscript. Many of the ideas and concepts presented in this review were formed during discussions with Laure Bally-Cuif and colleagues in Gifsur-Yvette. I am indebted to these people for their input and support. 


\section{REFERENCES}

Amacher, S. L. (2008). Emerging gene knockout technology in zebrafish: zinc-finger nucleases. Brief. Funct. Genomics Proteomics 7, 460-464.

Amir-Zilberstein, L., Blechman, J., Sztainberg, Y., Norton, W., Reuveny, A., Borodovsky, N., et al. (2012). Homeodomain protein Otp and activity-dependent splicing modulate neuronal adaptation to stress. Neuron 73, 279-291.

Arcos-Burgos, M., Jain, M., Acosta, M. T., Shively, S., Stanescu, H., Wallis, D., etal. (2010). A common variant of the latrophilin 3 gene, LPHN3, confers susceptibility to ADHD and predicts effectiveness of stimulant medication. Mol. Psychiatry 15, 1053-1066.

Arime, Y., Kubo, Y., and Sora, I. (2011). Animal models of attentiondeficit/hyperactivity disorder. Biol. Pharm. Bull. 34, 1373-1376.

Arnsten, A. F. (2007). Catecholamine and second messenger influences on prefrontal cortical networks of "representational knowledge": a rational bridge between genetics and the symptoms of mental illness. Cereb. Cortex 17(Suppl. 1), i6-i15.

Aspatwar, A., Tolvanen, M. E., Jokitalo, E., Parikka, M., Ortutay, C., Harjula, S. K., et al. (2013). Abnormal cerebellar development and ataxia in CARP VIII morphant zebrafish. Hum. Mol. Genet. 22, 417-432.

Bailey, A. J., Braeutigam, S., Jousmaki, V., and Swithenby, S. J. (2005). Abnormal activation of face processing systems at early and intermediate latency in individuals with autism spectrum disorder: a magnetoencephalographic study. Eur. J. Neurosci. 21, 2575-2585.

Banaschewski, T., Becker, K., Scherag, S., Franke, B., and Coghill, D. (2010) Molecular genetics of attentiondeficit/hyperactivity disorder: an overview. Eur. Child Adolesc. Psychiatry 19, 237-257.

Baraban, S. C. (2007). Emerging epilepsy models: insights from mice, flies, worms and fish. Curr. Opin. Neurol. 20, 164-168.

Barkley, R. A., Fischer, M., Smallish, L., and Fletcher, K. (2006). Young adult outcome of hyperactive children: adaptive functioning in major life activities. J. Am. Acad. Child Adolesc. Psychiatry 45, 192-202.

Baxendale, S., Holdsworth, C. J., Meza Santoscoy, P. L., Harrison, M. R., Fox, J., Parkin, C. A., et al. (2012). Identification of compounds with anticonvulsant properties in a zebrafish model of epileptic seizures. Dis. Models Mech. 5, 773-784.
Ben-David, E., and Shifman, S. (2012). Networks of neuronal genes affected by common and rare variants in autism spectrum disorders. PLoS Genet. 8:e1002556. doi: 10.1371/journal.pgen.1002556

Berquin, P. C., Giedd, J. N., Jacobsen, L. K., Hamburger, S. D., Krain, A. L. Rapoport, J. L., et al. (1998). Cerebellum in attention-deficit hyperactivity disorder: a morphometric MRI study. Neurology 50, 1087-1093.

Berridge, C. W., Devilbiss, D. M., Andrzejewski, M. E., Arnsten, A. F., Kelley, A. E., Schmeichel, B., et al. (2006). Methylphenidate preferentially increases catecholamine neurotransmission within the prefrontal cortex at low doses that enhance cognitive function. Biol. Psychiatry 60, 1111-1120.

Blader, P., and Strahle, U. (1998). Ethanol impairs migration of the prechordal plate in the zebrafish embryo. Dev. Biol. 201, 185-201.

Blaker-Lee, A., Gupta, S., McCammon, J. M., De Rienzo, G., and Sive, H. (2012). Zebrafish homologs of genes within 16p11.2, a genomic region associated with brain disorders, are active during brain development, and include two deletion dosage sensor genes. Dis. Models Mech. 5, 834-851.

Braff, D., Schork, N. J., and Gottesman, I. (2007). Endophenotyping schizophrenia. Am. J. Psychiatry 164 705-707.

Bretaud, S., Lee, S., and Guo, S. (2004) Sensitivity of zebrafish to environmental toxins implicated in Parkinson's disease. Neurotoxicol. Teratol. $26,857-864$.

Brockschmidt, A., Filippi, A., Charbel Issa, P., Nelles, M., Urbach, H., Eter N., et al. (2011). Neurologic and ocular phenotype in Pitt-Hopkins syndrome and a zebrafish model. Hum. Genet. 130, 645-655.

Burgess, H. A., and Granato, M. (2007). Modulation of locomotor activity in larval zebrafish during light adaptation. J. Exp. Biol. 210, 2526-2539.

Bush, G. (2010). Attention-deficit /hyperactivity disorder and attention networks. Neuropsychopharmacology 35, 278-300.

Buske, C., and Gerlai, R. (2011). Early embryonic ethanol exposure impairs shoaling and the dopaminergic and serotoninergic systems in adult zebrafish. Neurotoxicol. Teratol. 33, 698-707.

Castellanos, F. X., Giedd, J. N., Marsh, W. L., Hamburger, S. D., Vaituzis A. C., Dickstein, D. P., et al. (1996). Quantitative brain magnetic resonance imaging in attention-deficit hyperactivity disorder. Arch. Gen. Psychiatry 53, 607-616.

Chen, J., Patel, R., Friedman, T. C., and Jones, K. S. (2010). The behavioral and pharmacological actions of NMDA receptor antagonism are conserved in zebrafish larvae. Int. J. Comp. Psychol. 23, 82-90.

Cheng, Y. C., Scotting, P. J., Hsu, L. S. Lin, S. J., Shih, H. Y., Hsieh, F. Y., et al (2013). Zebrafish rgs4 is essential for motility and axonogenesis mediated by Akt signaling. Cell. Mol. Life Sci. 70, 935-950.

Choudhry, Z., Sengupta, S. M. Grizenko, N., Fortier, M. E., Thakur, G. A., Bellingham, J., et al. (2012). LPHN3 and attentiondeficit/hyperactivity disorder: interaction with maternal stress during pregnancy. J. Child Psychol. Psychiatry 53, 892-902.

Comings, D. E., Wu, S., Chiu, C. Ring, R. H., Gade, R., Ahn, C. et al. (1996). Polygenic inheritance of Tourette syndrome, stuttering, attention deficit hyperactivity, conduct, and oppositional defiant disorder: the additive and subtractive effect of the three dopaminergic genes DRD2, D beta H, and DAT1. Am. J. Med. Genet. 67, 264-288.

Cook, E. H., and Scherer, S. W. (2008). Copy-number variations associated with neuropsychiatric conditions. Nature 455, 919-923.

Cook, E. H., Stein, M. A., Krasowski, M. D., Cox, N. J., Olkon, D. M., Kieffer, J. E., et al. (1995). Association of attention-deficit disorder and the dopamine transporter gene. Am. J. Hum. Genet. 56, 993-998.

Cooper, B. (2001). Nature, nurture and mental disorder: old concepts in the new millennium. Br. J. Psychiatry Suppl. 178, s91-s101.

Cortese, S., Konofal, E., Lecendreux, M. Arnulf, I., Mouren, M.-C., Darra, F. et al. (2005). Restless legs syndrome and attention-deficit/hyperactivity disorder: a review of the literature. Sleep 28, 1007-1013.

Curado, S., Anderson, R. M., Jungblut, B., Mumm, J., Schroeter, E., and Stainier, D. Y. (2007). Conditional targeted cell ablation in zebrafish: a new tool for regeneration studies. Dev. Dyn. 236, 1025-1035.

Curran, S., Mill, J., Tahir, E. Kent, L., Richards, S., Gould, A., etal. (2001). Association study of a dopamine transporter polymorphism and attention deficit hyperactivity disorder in UK and Turkish samples. Mol. Psychiatry 6, 425-428.

Den Broeder, M. J., Van der Linde, H., Brouwer, J. R., Oostra, B. A., Willemsen, R., and Ketting, R. F. (2009).
Generation and characterization of FMR1 knockout zebrafish. PLoS ONE 4:e7910. doi: 10.1371/journal.pone.0007910

De Rienzo, G., Bishop, J. A., Mao, Y., Pan, L., Ma, T. P., Moens, C. B., etal. (2011). Discl regulates both $\beta$-catenin-mediated and noncanonical Wnt signaling during vertebrate embryogenesis. FASEB J. 25, 41844197.

Domene, S., Stanescu, H., Wallis, D., Tinloy, B., Pineda, D. E., Kleta, R., et al. (2011). Screening of human LPHN3 for variants with a potential impact on ADHD susceptibility. Am. J. Med. Genet. B Neuropsychiatr. Genet. 156B, 11-18.

Eaton, L. (2008). Healthcare Commission's standards of psychiatric care. Ment. Health Today 5.

Ebstein, R. P., Novick, O., Umansky, R., Priel, B., Osher, Y., Blaine, D., etal. (1996). Dopamine D4 receptor (D4DR) exon III polymorphism associated with the human personality trait of Novelty Seeking. Nat. Genet. 12, 78-80.

Echevarria, D. J., Jouandot, D. J., and Toms, C. N. (2011). Assessing attention in the zebrafish: are we there yet? Prog. Neuropsychopharmacol. Biol. Psychiatry 35, 1416-1420.

Eddins, D., Cerutti, D., Williams, P., Linney, E., and Levin, E. D. (2010). Zebrafish provide a sensitive model of persisting neurobehavioral effects of developmental chlorpyrifos exposure: comparison with nicotine and pilocarpine effects and relationship to dopamine deficits. Neurotoxicol. Teratol. 32, 99-108.

Einat, H., Manji, H. K., and Belmaker, R. H. (2003). New approaches to modeling bipolar disorder. Psychopharmacol. Bull. 37, 47-63.

Elia, J., Gai, X., Xie, H. M., Perin, J. C., Geiger, E., Glessner, J. T., et al. (2009). Rare structural variants found in attention-deficit hyperactivity disorder are preferentially associated with neurodevelopmental genes. Mol. Psychiatry 15, 637-646.

Faraone, S. V., Perlis, R. H., Doyle, A. E., Smoller, J. W., Goralnick, J. J., Holmgren, M. A., et al. (2005). Molecular genetics of attentiondeficit/hyperactivity disorder. Biol. Psychiatry 57, 1313-1323.

Farokhashtiani, T., Mirabzadeh, A., Olad Nabi, M., Magham, Z. G., Khorshid, H. R., Najmabadi, H., et al. (2011). Reversion of the human calreticulin gene promoter to the ancestral type as a result of a novel psychosis-associated mutation. Prog. Neuropsychopharmacol. Biol. Psychiatry 35, 541-544. 
Fernandes, Y., and Gerlai, R. (2009). Long-term behavioral changes in response to early developmental exposure to ethanol in zebrafish. Alcohol. Clin. Exp. Res. 33, 601-609.

Fero, K., Yokogawa, T., and Burgess, H. A. (2011). "The behavioral repertoire of larval zebrafish," in Zebrafish Models in Neurobehavioral Research, eds A. V. Kalueff and J. M. Cachat (New York: Springer), 249-291.

Fetcho, J. R., and Liu, K. S. (1998). Zebrafish as a model system for studying neuronal circuits and behavior. Ann. N. Y. Acad. Sci. 860, 333-345.

Flynn, S. W., Lang, D. J., Mackay, A. L., Goghari, V., Vavasour, I. M., Whittall, K. P., et al. (2003). Abnormalities of myelination in schizophrenia detected in vivo with MRI, and postmortem with analysis of oligodendrocyte proteins. Mol. Psychiatry 8, $811-820$

Frazer, K. A., Murray, S. S., Schork, N. J., and Topol, E. J. (2009). Human genetic variation and its contribution to complex traits. Nat. Rev. 10, 241-251.

Friedrich, T., Lambert, A. M., Masino, M. A., and Downes, G. B. (2012). Mutation of zebrafish dihydrolipoamide branched-chain transacylase E2 results in motor dysfunction and models maple syrup urine disease. Dis. Models Mech. 5, 248-258.

Fujimoto, E., Stevenson, T. J., Chien, C. B., and Bonkowsky, J. L. (2011). Identification of a dopaminergic enhancer indicates complexity in vertebrate dopamine neuron phenotype specification. Dev. Biol. 352, 393-404.

Gauthier, J., Champagne, N., Lafreniere, R. G., Xiong, L., Spiegelman, D., Brustein, E., etal. (2010). De novo mutations in the gene encoding the synaptic scaffolding protein SHANK3 in patients ascertained for schizophrenia. Proc. Natl. Acad. Sci. U.S.A. 107, 7863-7868.

Geschwind, D. H. (2008). Autism: many genes, common pathways? Cell 135 , 391-395.

Geschwind, D. H. (2011). Genetics of autism spectrum disorders. Trends Cogn. Sci. 15, 409-416.

Geschwind, D. H., and Levitt, P. (2007) Autism spectrum disorders: developmental disconnection syndromes. Curr. Opin. Neurobiol. 17, 103-111.

Girard, S. L., Dion, P. A., and Rouleau, G. A. (2012). Schizophrenia genetics: putting all the pieces together. Curr. Neurol. Neurosci. Rep. 12, 261-266.

Girard, S. L., Gauthier, J., Noreau, A., Xiong, L., Zhou, S., Jouan, L., et al. (2011). Increased exonic de novo mutation rate in individuals with schizophrenia. Nat. Genet. 43 , 860-863.

Girirajan, S., and Eichler, E. E. (2010) Phenotypic variability and genetic susceptibility to genomic disorders. Hum. Mol. Genet. 19, R176-R187.

Gizer, I. R., Ficks, C., and Waldman, I. D. (2009). Candidate gene studies of ADHD: a meta-analytic review. Hum. Genet. 126, 51-90.

Golzio, C., Willer, J., Talkowski, M. E. Oh, E. C., Taniguchi, Y., Jacquemont, S., et al. (2012). KCTD13 is a major driver of mirrored neuroanatomical phenotypes of the $16 \mathrm{p} 11.2$ copy number variant. Nature 485 , 363-367.

Gothelf, D., Presburger, G., Levy, D. Nahmani, A., Burg, M., Berant, M. et al. (2004). Genetic, developmental and physical factors associated with attention deficit hyperactivity disorder in patients with velocardiofacial syndrome. Am. J. Med. Genet. B Neuropsychiatr. Genet. 126B, 116-121.

Gottesman, I., and Gould, T. D. (2003). The endophenotype concept in psychiatry: etymology and strategic intentions. Am. J. Psychiatry 160 636-645.

Guidry, J., and Kent, T. A. (1999). New genetic hypothesis of schizophrenia Med. Hypotheses 52, 69-75.

Hawi, Z., Dring, M., Kirley, A., Foley, D., Kent, L., Craddock, N., et al. (2002). Serotonergic system and attention deficit hyperactivity disorder (ADHD): a potential susceptibility locus at the 5-HT(1B) receptor gene in 273 nuclear families from a multi-centre sample. Mol. Psychiatry 7, 718-725.

Higashijima, S., Masino, M. A., Mandel, G., and Fetcho, J. R. (2003). Imaging neuronal activity during zebrafish behavior with a genetically encoded calcium indicator. J. Neurophysiol. 90 , 3986-3997.

Huang, P., Xiao, A., Zhou, M., Zhu, Z., Lin, S., and Zhang, B. (2011). Heritable gene targeting in zebrafish using customized TALENs. Nat. Biotechnol. 29, 699-700.

Irons, T. D., MacPhail, R. C., Hunter, D. L., and Padilla, S. (2010). Acute neuroactive drug exposures alter locomotor activity in larval zebrafish. Neurotoxicol. Teratol. 32, 84-90.

Iwase, S., Lan, F., Bayliss, P., De la Torre-Ubieta, L., Huarte, M., Qi, H. H., et al. (2007). The X-linked mental retardation gene SMCX/JARID1C defines a family of histone $\mathrm{H} 3$ lysine 4 demethylases. Cell 128, 1077-1088.

Kendler, K. S., and Neale, M. C. (2010) Endophenotype: a conceptual analysis. Mol. Psychiatry 15, 789-797.
Knudson, A. G. (1971). Mutation and cancer: statistical study of retinoblastoma. Proc. Natl. Acad. Sci. U.S.A. 68 , 820-823.

Kokel, D., Bryan, J., Laggner, C., White, R., Cheung, C. Y., Mateus, R., et al. (2010). Rapid behaviorbased identification of neuroactive small molecules in the zebrafish. Nat. Chem. Biol. 6, 231-237.

Komoike, Y., Shimojima, K., Liang, J. S., Fujii, H., Maegaki, Y., Osawa, M., et al. (2010). A functional analysis of GABARAP on 17p13.1 by knockdown zebrafish. J. Hum. Genet. 55, 155-162.

Laggner, C., Kokel, D., Setola, V., Tolia, A., Lin, H., Irwin, J. J., et al. (2012). Chemical informatics and target identification in a zebrafish phenotypic screen. Nat. Chem. Biol. 8, 144-146.

LaHoste, G. J., Swanson, J. M., Wigal, S. B., Glabe, C., Wigal, T., King, N., et al. (1996). Dopamine D4 receptor gene polymorphism is associated with attention deficit hyperactivity disorder. Mol. Psychiatry 1, 121-124.

Lange, M., Norton, W., Coolen, M., Chaminade, M., Merker, S., Proft, F., et al. (2012). The ADHDsusceptibility gene lphn3.1 modulates dopaminergic neuron formation and locomotor activity during zebrafish development. Mol. Psychiatry 17, 946-954.

Laucht, M., Skowronek, M. H., Becker, K., Schmidt, M. H., Esser, G., Schulze, T. G., et al. (2007). Interacting effects of the dopamine transporter gene and psychosocial adversity on attentiondeficit/hyperactivity disorder symptoms among 15-year-olds from a high-risk community sample. Arch. Gen. Psychiatry 64, 585-590.

Lesch, K. P., Selch, S., Renner, T. J., Jacob, C., Nguyen, T. T., Hahn, T., et al. (2011). Genome-wide copy number variation analysis in attentiondeficit/hyperactivity disorder: association with neuropeptide $\mathrm{Y}$ gene dosage in an extended pedigree. $\mathrm{Mol}$. Psychiatry 16, 491-503.

Lesch, K. P., Timmesfeld, N., Renner, T. J., Halperin, R., Roser, C., Nguyen, T. T., et al. (2008). Molecular genetics of adult ADHD: converging evidence from genome-wide association and extended pedigree linkage studies. $J$ Neural. Transm. 115, 1573-1585.

Li, J., Wang, Y., Zhou, R., Zhang, H., Yang, L., Wang, B., et al. (2007). Association between polymorphisms in serotonin transporter gene and attention deficit hyperactivity disorder in Chinese Han subjects. Am. J. Med. Genet. B Neuropsychiatr. Genet. 144B, 14-19.
Lillesaar, C., Stigloher, C., Tannhauser, B., Wullimann, M. F., and BallyCuif, L. (2009). Axonal projections originating from raphe serotonergic neurons in the developing and adult zebrafish, Danio rerio, using transgenics to visualize raphe-specific petl expression. J. Comp. Neurol. 512, 158-182.

Lin, S. L., Chang, S. J., and Ying, S. Y. (2006). First in vivo evidence of microRNA-induced fragile X mental retardation syndrome. Mol. Psychiatry 11, 616-617.

Lionel, A. C., Crosbie, J., Barbosa, N., Goodale, T., Thiruvahindrapuram, B., Rickaby, J., etal. (2011). Rare copy number variation discovery and cross-disorder comparisons identify risk genes for ADHD. Sci. Transl. Med. 3, 95 ra75.

Lisman, J. E., Coyle, J. T., Green, R. W., Javitt, D. C., Benes, F. M., Heckers, S., et al. (2008). Circuit-based framework for understanding neurotransmitter and risk gene interactions in schizophrenia. Trends Neurosci. 31, 234-242.

Lord, C., Cook, E. H., Leventhal, B. L., and Amaral, D. G. (2000). Autism spectrum disorders. Neuron 28, 355-363.

Lord, C. E. (2010). Autism: from research to practice. Am. Psychol. 65, 815-826.

Marks, C., West, T. N., Bagatto, B., and Moore, F. B.-G. (2005). Developmental environment alters conditional aggression in zebrafish. Copeia 4, 901-908.

Menelaou, E., and Svoboda, K. R. (2009). Secondary motoneurons in juvenile and adult zebrafish: axonal pathfinding errors caused by embryonic nicotine exposure. J. Comp. Neurol. 512, 305-322.

Millar, J. K., Christie, S., Semple, C. A., and Porteous, D. J. (2000). Chromosomal location and genomic structure of the human translin-associated factor $\mathrm{X}$ gene (TRAX; TSNAX) revealed by intergenic splicing to DISC1, a gene disrupted by a translocation segregating with schizophrenia. Genomics 67, 69-77.

Mitchell, K. (2011). The miswired brain: making connections from neurodevelopment to psychopathology. BMC Biol. 9:23. doi: 10.1186/ 1741-7007-9-23

Mitchell, K., and Porteus, D. J. (2011). Rethinking the genetic architecture of schizophrenia. Psychol. Med. 41, 19-32.

Molina, B. S., and Pelham, W. E. (2003). Childhood predictors of adolescent substance use in a longitudinal study 
of children with ADHD. J. Abnorm. Psychol. 112, 497-507.

Morris, J. A. (2009). Zebrafish: a model system to examine the neurodevelopmental basis of schizophrenia. Prog. Brain Res. 179, 97-106.

Mueser, K. T., and McGurk, S. R. (2004). Schizophrenia. Lancet 363 , 2063-2072.

Nagel, G., Szellas, T., Huhn, W. Kateriya, S., Adeishvili, N., Berthold, P., et al. (2003). Channelrhodopsin-2, a directly light-gated cation-selective membrane channel. Proc. Natl. Acad. Sci. U.S.A. 100, 13940-13945.

Norton, W., and Bally-Cuif, L. (2010). Adult zebrafish as a model organism for behavioural genetics. BMC Neurosci. 11:90. doi: 10.1186/14712202-11-90

Norton, W. H., Stumpenhorst, K., FausKessler, T., Folchert, A., Rohner, N., Harris, M. P., et al. (2011). Modulation of Fgfrla signaling in zebrafish reveals a genetic basis for the aggression-boldness syndrome. $J$. Neurosci. 31, 13796-13807.

O’Sullivan, M. L., De Wit, J., Savas, J. N., Comoletti, D., Otto-Hitt, S., Yates, J. R., et al. (2012). FLRT proteins are endogenous latrophilin ligands and regulate excitatory synapse development. Neuron 73, 903-910.

Parker, M. O., Millington, M. E., Combe, F. J., and Brennan, C. H. (2012). Development and implementation of a three-choice serial reaction time task for zebrafish (Danio rerio) Behav. Brain Res. 227, 73-80.

Paul, S. M., Mytelka, D. S., Dunwiddie, C. T., Persinger, C. C., Munos, B. H., Lindborg, S. R., et al. (2010). How to improve R\&D productivity: the pharmaceutical industry's grand challenge. Nat. Rev. Drug Discov. 9, 203-214.

Peterson, R. T., Link, B. A., Dowling, J. E., and Schreiber, S. L. (2000). Small molecule developmental screens reveal the logic and timing of vertebrate development. Proc. Natl. Acad. Sci. U.S.A. 97, 12965-12969.

Polanczyk, G., De Lima, M. S., Horta, B. L., Biederman, J., and Rohde, L. A. (2007). The worldwide prevalence of ADHD: a systematic review and metaregression analysis. Am. J. Psychiatry 164, 942-948.

Porteous, D. J., Millar, J. K., Brandon, N. J., and Sawa, A. (2011). DISC1 at 10: connecting psychiatric genetics and neuroscience. Trends Mol. Med. 17, 699-706.

Purper-Ouakil, D., Wohl, M., Mouren, M. C., Verpillat, P., Ades, J., and Gorwood, P. (2005). Meta-analysis of family-based association studies between the dopamine transporter gene and attention deficit hyperactivity disorder. Psychiatr. Genet. 15, 53-59.

Qi, H. H., Sarkissian, M., Hu, G. Q., Wang, Z., Bhattacharjee, A., Gordon, D. B., et al. (2010). Histone H4K20/H3K9 demethylase PHF8 regulates zebrafish brain and craniofacial development. Nature 466, 503-507.

Rihel, J., Prober, D. A., Arvanites, A., Lam, K., Zimmerman, S., Jang, S., et al. (2010). Zebrafish behavioral profiling links drugs to biological targets and rest/wake regulation. Science 327, 348-351.

Rommelse, N. N. (2008). Endophenotypes in the genetic research of ADHD over the last decade: have they lived up to their expectations? Expert Rev. Neurother. 8, 1425-1429.

Rosenberg, R. E., Daniels, A. M., Law, J. K., Law, P. A., and Kaufmann, W E. (2009). Trends in autism spectrum disorder diagnoses: 1994-2007. J. Autism. Dev. Disord. 39, 1099-1111. Rubia, K. (2011). “Cool” inferior frontostriatal dysfunction in attentiondeficit/hyperactivity disorder versus "hot" ventromedial orbitofrontallimbic dysfunction in conduct disorder: a review. Biol. Psychiatry 69 e69-e87.

Ryu, S., Mahler, J., Acampora, D., Holzschuh, J., Erhardt, S., Omodei D., et al. (2007). Orthopedia homeodomain protein is essential for diencephalic dopaminergic neuron development. Curr. Biol. 17, 873-880.

Sallinen, V., Sundvik, M., Reenila, I., Peitsaro, N., Khrustalyov, D., Anichtchik, O., et al. (2009). Hyperserotonergic phenotype after monoamine oxidase inhibition in larval zebrafish. J. Neurochem. 109, 403-415.

Sander, J. D., Cade, L., Khayter, C., Reyon, D., Peterson, R. T., Joung, J. K. et al. (2011). Targeted gene disruption in somatic zebrafish cells using engineered TALENs. Nat. Biotechnol. 29, 697-698.

Sarter, M., Hagan, J., and Dudchenko, P. (1992). Behavioral screening for cognition enhancers: from indiscriminate to valid testing: part I. Psychopharmacology 107, 144-159.

Schmidt, S., and Petermann, F. (2009). Developmental psychopathology: attention deficit hyperactivity disorder (ADHD). BMC Psychiatry 9:58. doi: 10.1186/1471-244X-9-58

Sebat, J. (2007). Major changes in our DNA lead to major changes in our thinking. Nat. Genet. 39, S3-S5.

Sebat, J., Levy, D. L., and McCarthy, S. E. (2009). Rare structural variants in schizophrenia: one disorder, multiple mutations; one mutation, multiple disorders. Trends Genet. 25, 528-535.

Seibt, K. J., Oliveira Rda, L., Zimmermann, F. F., Capiotti, K. M., Bogo, M. R., Ghisleni, G., et al. (2010). Antipsychotic drugs prevent the motor hyperactivity induced by psychotomimetic MK-801 in zebrafish (Danio rerio). Behav. Brain Res. 214 417-422.

Seibt, K. J., Piato, A. L., Da Luz Oliveira, R., Capiotti, K. M., Vianna, M. R., and Bonan, C. D. (2011). Antipsychotic drugs reverse MK-801-induced cognitive and social interaction deficits in zebrafish (Danio rerio). Behav. Brain Res. 224, 135-139.

Sharp, S. I., McQuillin, A., and Gurling, H. M. (2009). Genetics of attention-deficit hyperactivity disorder (ADHD). Neuropharmacology 57, 590-600.

Silva, J. P., Lelianova, V. G., Ermolyuk, Y. S., Vysokov, N., Hitchen, P. G. Berninghausen, O., et al. (2011). Latrophilin 1 and its endogenous ligand Lasso/teneurin-2 form a high-affinity transsynaptic receptor pair with signaling capabilities. Proc. Natl. Acad. Sci. U.S.A. 108, 12113-12118.

Singh, K. K., De Rienzo, G., Drane, L., Mao, Y., Flood, Z., Madison, J., et al. (2011). Common DISC1 polymorphisms disrupt Wnt/GSK3beta signaling and brain development. $\mathrm{Neu}$ ron $72,545-558$.

Song, Y., Willer, J. R., Scherer, P. C., Panzer, J. A., Kugath, A., Skordalakes, E., et al. (2010). Neural and synaptic defects in slytherin, a zebrafish model for human congenital disorders of glycosylation. PLOS ONE 5:e13743. doi: 10.1371/journal.pone.0013743

Souza, B. R., Romano-Silva, M. A., and Tropepe, V. (2011). Dopamine D2 receptor activity modulates Akt signaling and alters GABAergic neuron development and motor behavio in zebrafish larvae. J. Neurosci. 31, 5512-5525.

Sullivan, P. F., Kendler, K. S., and Neale, M. C. (2003). Schizophrenia as a complex trait: evidence from a metaanalysis of twin studies. Arch. Gen. Psychiatry 60, 1187-1192.

Svoboda, K. R., Vijayaraghavan, S. and Tanguay, R. L. (2002). Nicotinic receptors mediate changes in spinal motoneuron development and axonal pathfinding in embryonic zebrafish exposed to nicotine. $\mathrm{J}$. Neu rosci. 22, 10731-10741.

Swanson, J., Castellanos, F. X., Murias, M., LaHoste, G., and Kennedy, J. (1998). Cognitive neuroscience of attention deficit hyperactivity disorder and hyperkinetic disorder. Curr. Opin. Neurobiol 8, 263-271.
Sylvain, N. J., Brewster, D. L., and Ali, D. W. (2010). Zebrafish embryos exposed to alcohol undergo abnormal development of motor neurons and muscle fibers. Neurotoxicol. Teratol. 32, 472-480.

Sylvain, N. J., Brewster, D. L., and Ali, D. W. (2011). Embryonic ethanol exposure alters synaptic properties at zebrafish neuromuscular junctions. Neurotoxicol. Teratol. 33, 313-321.

Tal, T. L., Franzosa, J. A., Tilton, S. C., Philbrick, K. A., Iwaniec, U. T., Turner, R. T., et al. (2012). MicroRNAs control neurobehavioral development and function in zebrafish. FASEB J. 26, 1452-1461.

Tarabeux, J., Champagne, N., Brustein, E., Hamdan, F. F., Gauthier, J., Lapointe, M., et al. (2010). De novo truncating mutation in Kinesin 17 associated with schizophrenia. Biol. Psychiatry 68, 649-656.

Tay, T. L., Ronneberger, O., Ryu, S., Nitschke, R., and Driever, W. (2011). Comprehensive catecholaminergic projectome analysis reveals single-neuron integration of zebrafish ascending and descending dopaminergic systems. Nat. Commun. 2, 171.

Thapar, A., Rice, F., Hay, D., Boivin, J., Langley, K., Van den Bree, M., et al. (2009). Prenatal smoking might not cause attention-deficit/hyperactivity disorder: evidence from a novel design. Biol. Psychiatry 66, 722-727.

Thornton, G. K., and Woods, C. G. (2009). Primary microcephaly: do all roads lead to Rome? Trends Genet. 25, 501-510.

Toro, R., Konyukh, M., Delorme, R., Leblond, C., Chaste, P., Fauchereau, F., et al. (2010). Key role for gene dosage and synaptic homeostasis in autism spectrum disorders. Trends Genet. 26, 363-372.

Tropepe, V., and Sive, H. L. (2003). Can zebrafish be used as a model to study the neurodevelopmental causes of autism? Genes Brain Behav. 2, 268-281.

Tsend-Ayush, E., O’Sullivan, L. A., Grutzner, F. S., Onnebo, S. M., Lewis, R. S., Delbridge, M. L., et al. (2005). RBMX gene is essential for brain development in zebrafish. Dev. Dyn. 234, 682-688.

Tucker, B., Richards, R. I., and Lardelli, M. (2006). Contribution of mGluR and Fmrl functional pathways to neurite morphogenesis, craniofacial development and fragile X syndrome. Hum. Mol. Genet. 15, 3446-3458.

Valiente, M., and Marin, O. (2010). Neuronal migration mechanisms in development and disease. Curr. Opin. Neurobiol. 20, 68-78. 
Vandenbergh, D. J., Persico, A. M., Hawkins, A. L., Griffin, C. A., Li, X., Jabs, E. W., et al. (1992). Human dopamine transporter gene (DAT1) maps to chromosome 5p15.3 and displays a VNTR. Genomics 14, 1104 1106.

Veleri, S., Bishop, K., Dalle Nogare, D. E., English, M. A., Foskett, T. J., Chitnis, A., et al. (2012). Knockdown of Bardet-Biedl syndrome gene BBS9/PTHB1 leads to cilia defects. PLoS ONE 7:e34389. doi: 10.1371/journal.pone.0034389

Veltman, J. A., and Brunner, H. G. (2012). De novo mutations in human genetic disease. Nat. Rev. Genet. 13, 565-575.

Verkerk, A. J., Pieretti, M., Sutcliffe, J. S., Fu, Y. H., Kuhl, D. P., Pizzuti, A., et al. (1991). Identification of a gene (FMR-1) containing a CGG repeat coincident with a breakpoint cluster region exhibiting length variation in fragile X syndrome. Cell 65, 905-914.

Walitza, S., Renner, T. J., Dempfle, A., Konrad, K., Wewetzer, C., Halbach, A., et al. (2005). Transmission disequilibrium of polymorphic variants in the tryptophan hydroxylase- 2 gene in attention-deficit/hyperactivity disorder. Mol. Psychiatry 10, 1126-1132.
Wallis, D., Hill, D. S., Mendez, I. A., Abbott, L. C., Finnell, R. H., Wellman, P. J., et al. (2012). Initial characterization of mice null for Lphn3, a gene implicated in ADHD and addiction. Brain Res. 1463, 85-92.

Walsh, C. A. (1999). Genetic malformations of the human cerebral cortex. Neuron 23, 19-29.

Walsh, C. A., and Engle, E. C. (2010) Allelic diversity in human developmental neurogenetics: insights into biology and disease. Neuron 68, 245-253.

Walsh, T., McClellan, J. M., McCarthy, S. E., Addington, A. M., Pierce, S. B., Cooper, G. M., et al. (2008). Rare structural variants disrupt multiple genes in neurodevelopmental pathways in schizophrenia. Science 320 , 539-543.

Weinberger, D. R. (1995). From neuropathology to neurodevelopment Lancet 346, 552-557.

West-Eberhard, M. J. (2005). Developmental plasticity and the origin of species differences. Proc. Natl. Acad. Sci. U.S.A. 102(Suppl. 1), 6543-6549.

Williams, N. M., Zaharieva, I., Martin, A., Langley, K., Mantripragada, K., Fossdal, R., et al. (2010). Rare chromosomal deletions and duplications in attention-deficit hyperactivity disorder: a genome-wide analysis Lancet 376, 1401-1408.

Wood, A. C., Rijsdijk, F., Asherson, P., and Kuntsi, J. (2009). Hyperactive-impulsive symptom scores and oppositional behaviours reflect alternate manifestations of a single liability. Behav. Genet. 39, 447-460.

World Health Organisation (WHO). (2008). The Global Burden of Disease. 2004 Update. Geneva: WHO.

Xu, B., Roos, J. L., Levy, S., Van Rensburg, E. J., Gogos, J. A., and Karayiorgou, M. (2008). Strong association of de novo copy number mutations with sporadic schizophrenia. Nat. Genet 40, 880-885.

Yoshida, T., and Mishina, M. (2008) Zebrafish orthologue of mental retardation protein IL1RAPL1 regulates presynaptic differentiation. Mol. Cell. Neurosci. 39, 218-228.

Zhang, F., Wang, L. P., Brauner, M. Liewald, J. F., Kay, K., Watzke, N., et al. (2007). Multimodal fast optical interrogation of neural circuitry. Nature 446, 633-639.

Zweier, C., De Jong, E. K., Zweier, M. Orrico, A., Ousager, L. B., Collins,
A. L., et al. (2009). CNTNAP2 and NRXN1 are mutated in autosomalrecessive Pitt-Hopkins-like mental retardation and determine the level of a common synaptic protein in Drosophila. Am. J. Hum. Genet. 85, 655-666.

Conflict of Interest Statement: The author declares that the research was conducted in the absence of any commercial or financial relationships that could be construed as a potential conflict of interest.

Received: 24 January 2013; accepted: 09 April 2013; published online: 26 April 2013.

Citation: Norton WHJ (2013) Toward developmental models of psychiatric disorders in zebrafish. Front. Neural Circuits 7:79. doi: 10.3389/fncir.2013.00079

Copyright (C) 2013 Norton. This is an open-access article distributed under the terms of the Creative Commons Attribution License, which permits use, distribution and reproduction in other forums, provided the original authors and source are credited and subject to any copyright notices concerning any thirdparty graphics etc. 